\title{
A Termodinâmica da Vida
}

Material didático elaborado pelas autoras:

\author{
Mayara Gomes da Silva \\ Universidade Estadual da Paraíba (UEPB) \\ $\triangle$ mayaragomesec@gmail.com \\ Alessandra Costa \\ Universidade Estadual da Paraíba (UEPB) \\ 凹alecosta_@outlook.com \\ Márcia Adelino da Silva Dias \\ Universidade Estadual da Paraíba (UEPB) \\ $\triangle$ adelinomarcia@yahoo.com.br \\ Karla Patrícia de Oliveira Luna \\ Universidade Estadual da Paraíba (UEPB) \\ $\triangle$ karlaceatox@yahoo.com.br
}




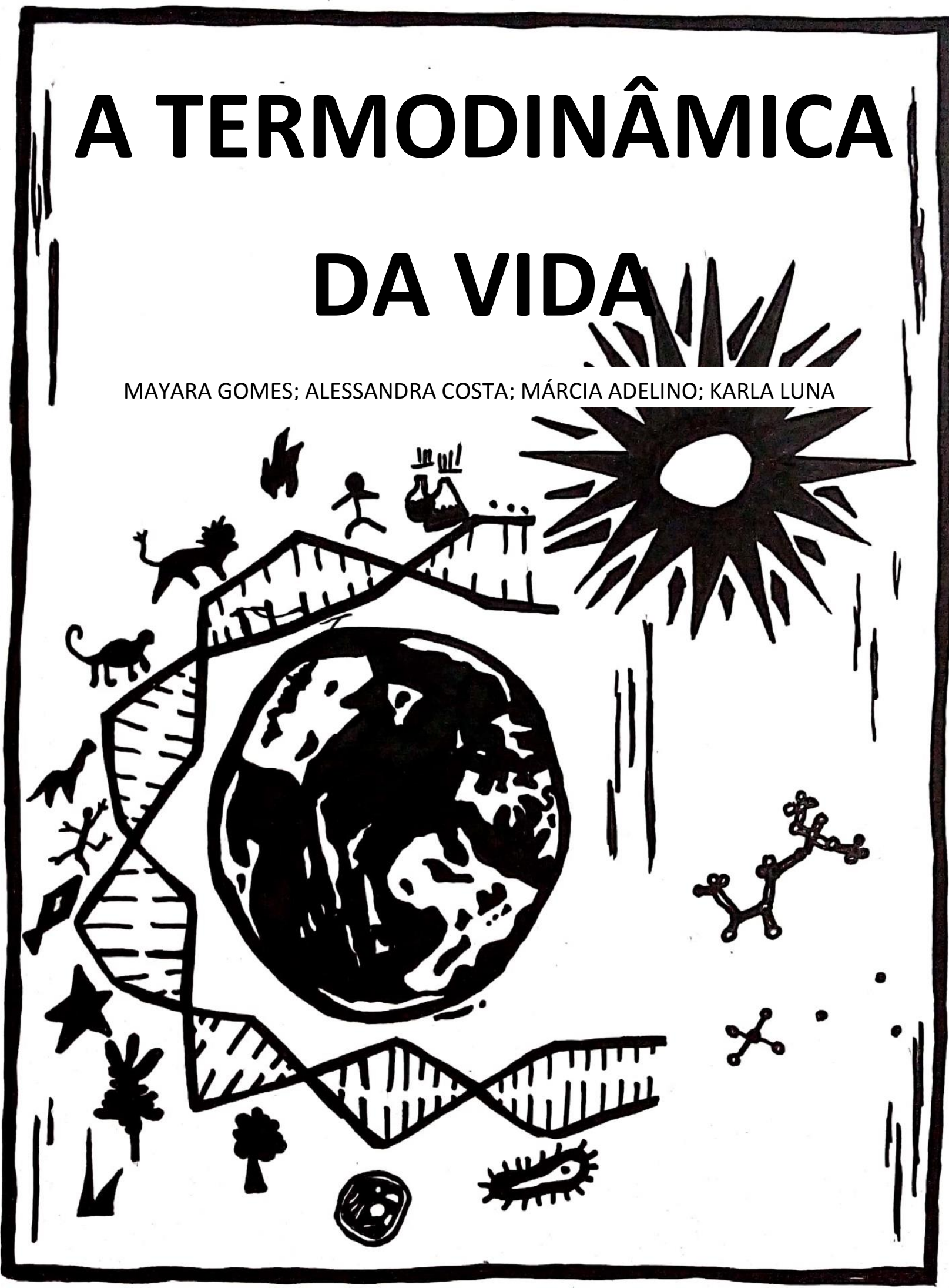

Campina Grande - Paraíba - Brasil - 1 a Edição - MARÇO DE 2021 


\section{APRESENTAÇÃO}

É com honra e alegria que apresento este cordel. Um importante recurso para o ensino da termodinâmica.

A produção é parte de uma dissertação que teve como objetivo principal relacionar a Ciência da Termodinâmica com as Ciências da Complexidade. Claro, este não foi um trabalho fácil, porém prazeroso e que presenteia a ciência com um produto inovador no que diz respeito ao ensino de Biofísica: a oportunidade de visualizar a termodinâmica de maneira lúdica.

No âmbito do ensino de ciências, mais que importante, é imprescindível, levar estudantes de pós-graduação a entender a importância de produções deste tipo, aptas a contribuir com a prática docente em todos os níveis.

Neste sentido, sinto-me grata em poder ter orientado o trabalho que deu origem a este cordel, material dotado de relações entre a oralidade, a escrita e as nossas raízes histórico-culturais, que certamente, vem a promover uma nova forma de ensinar e aprender Biofísica.

Atenciosamente,

Profa. Dra. Karla Luna 


\title{
A TERMODINÂMICA DA VIDA
}

NUMA ABORDAGEM PARA O ENSINO DE BIOFÍSICA

\author{
01 - As ciências do fogo trouxeram \\ Consigo muita inovação \\ Inseriram na dinâmica \\ A sua transformação \\ Calor e chamas libertas \\ Causaram revolução.
}

$\mathbf{0 2}$ - As reações químicas do fogo

Nos auges industriais

Lá no século dezenove

Foram itens essenciais

Para girar máquinas térmicas

E problemáticas sociais.

$\mathbf{0 3}$ - As ciências com o seu papel

De contribuir com as sociedades

Trataram logo de estudar

O calor e as suas propriedades

Desse jeito, cientistas acharam difícil

Negar a complexidade. 
04 - Ao observarem o calor

Produzindo energia mecânica

Juntaram tudo o que tinham

Fundaram a Termodinâmica

Calor, matéria e interação

Distantes da dualidade platônica.

05 - A partir desses estudos

Chegamos a compreensão

Das interfaces das ciências

Física e vida em ação

Das máquinas à segunda Lei

Natureza, tempo e educação.

06 - No campo da Termodinâmica

O calor é energia

Tal como a energia elétrica

A ciência já discutia

Que a energia térmica do Sol

É indispensável à vida.

07 - A primeira lei diz respeito

À conservação da energia 
Em um sistema isolado

A energia não é criada ou destruída

É conservada ou constante

Apesar das transformações ocorridas.

$\mathbf{0 8}$ - Esse é um ponto interessante

Dessa nossa discussão

Pois se a energia não se altera

Apesar da transformação

É possível reverter os processos

Invertendo a direção?

09 - Imagine um dia quente

E um cubo de gelo que derreteu

Será que naturalmente é possível

Reverter o que aconteceu?

A água espontaneamente volta a ser gelo

Apesar do que sucedeu?

10 - Além disso, você hoje

É idêntico a quando nasceu?

É possível tornar bebê

Alguém que envelheceu?

Ou mesmo reverter o processo 
Trazendo vida a quem morreu?

11 - Por incrível que pareça

Essa é uma problemática

Que surge na Revolução Industrial

Lá dentro das grandes fábricas

Onde a preocupação central era

$\mathrm{O}$ rendimento das máquinas.

12 - Estudando as máquinas térmicas

Carnot evidenciou

Que o trabalho pode sim

Ser dissipado em calor

Mas aproveitar todo o calor em trabalho

É impossível, pois parte se dissipou.

13 - É nesse contexto que surge

Uma grande novidade

Nos processos naturais

Existe a irreversibilidade

E o tempo unidirecional

Marcando a transitoriedade. 
14 - É a Segunda Lei que trata

Da irreversibilidade na natureza

Com uma função de estado

Que ressalta a incerteza

Trata-se da Entropia

E das suas sutilezas.

15 - A Entropia refere-se

Ao número de possibilidades

À medida quantitativa

Da irreversibilidade

Aos diferentes estados

Possíveis na realidade.

16 - Alguns a chamam de desordem

Ou de desorganização

Afirmam que no universo

Ela cresce na direção

De aumentar promovendo

A descomplexificação.

17 - Então, como seria possível

Nessa entropia crescente

Que na Terra existisse 
Formas de seres viventes

Que evolutivamente criaram

estruturas surpreendentes?

18 - Não só criaram mas

Mantiveram a sua organização

Diante de eventos estocásticos

Ao longo da evolução

A vida desenvolveu meios

Para a sua continuação.

19 - Como sistemas abertos

Distantes do equilíbrio

Os seres vivos consistem

Em sistemas dissipativos

Trocando com o ambiente

Nutrientes, calor e resíduos.

20 - Dissipando energia solar

Os seres vivos formaram

Estruturas dissipativas

E se auto-organizaram

Com baixa entropia interna

E equilíbrio estacionário. 
21 - Estacionário porque

Estão em troca contínua

De matéria, informação

E também de energia

Se fosse um equilíbrio estático

Não haveria a vida.

22 - É tão tal que quando há

Essa equilibração

A morte logo alcança

A sua realização

Pois a vida é impossível

Longe da interação.

23 - Ordem a partir da desordem

Consiste em uma premissa

Para explicar como os seres

Em uma crescente entropia

Criaram o seu metabolismo

E a organizaram a vida.

24 - Ordem a partir da ordem

É outra prerrogativa 
Para elucidar que os genes

Carregam a continuidade da vida

Em um código organizado

Distante da entropia.

25 - Crescimento, desenvolvimento

E evolução biológica

São respostas dissipativas

Seguindo essa mesma lógica

Isso também se estende

À auto-organização ecológica.

26 - As mudanças energéticas

Também consistiram na chave

Para os ecossistemas

E a biodiversidade

Quanto mais energia disponível

Maior a complexidade.

27 -É nesse contexto que

Também se evidencia

Uma força que atua

Propiciando a vida

Levando a elaboração 
Da Lei da Sintropia.

28 - Sintropia e Entropia

Podem ser compreendidas

Como forças opostas

Mas complementares à vida

Que permitem aos ecossistemas

Atuarem em Sinergia.

29 - Algumas pessoas dizem

Que a Sinergia integra

A Linguagem do Amor

Falada pela Mãe-Terra

A atuação harmônica

De tudo o que se conecta.

30 - No entanto, o ser humano

Se tornou especialista

Em interferir nos ciclos

Aumentando a Entropia

Poluindo, desmatando

Ameaçando a vida. 
31 - Veja só a Amazônia

E o crescente desmatamento

Com a destruição de habitats

Sem nenhum consentimento

Resultando sem surpresa

Num crescente adoecimento.

32 - Pandemias, desmatamentos

E mudanças climáticas

Tudo isso está ligado

Constituindo problemáticas

Que ameaçam à vida

E as sociedades democráticas.

33 - E o que se pode fazer

Diante dessa destruição?

Como é possível viver

Em meio a essa ilusão

De que o ser humano não faz

Parte dessa integração?

34 - Nem tudo está perdido

Veja só a alternativa

De reflorestar as áreas 
Com a Agricultura Regenerativa

Melhorando o clima e vivendo

De forma não destrutiva.

35 - Podemos também esperançar

De modo realista e sábio

Não que tudo vá dar certo

Mas independente do resultado

Fazer algo que faça sentido

Com base na ética do cuidado

36 - Também é possível buscar

Nessa multiplicidade de visões

Um ponto comum de contato

Para construir relações

De autorresponsabilidade

Diante de todas essas situações.

37 - E se você sente que

A queda é inevitável

Ou que o abismo é grande

E a vida é mesmo instável

Abrir os paraquedas talvez seja

Uma ideia confortável. 
38 - Enquanto seres humanos

E profissionais da educação

Esperamos que este cordel

E toda nossa discussão

Fomente diálogos empáticos

E diversidade de expressão. 


\title{
SOBRE AS AUTORAS
}

\section{Mayara Gomes da Silva}

Licenciada em Ciências Biológicas, especialista e mestranda (em conclusão) na área de Ensino de Ciências (UEPB). Psicóloga em formação (UFPB) e integrante o Grupo de Estudos da Complexidade e da Vida - GRECOMVIDA (UEPB). Conheci o "folhete" por meio de vovô João quando era criança. E conforme fui crescendo e conhecendo as coisas, tornei-me amante da Literatura de Cordel. É uma felicidade imensa ver esses artefatos populares que carregam tanto da nossa história, cultura, identidade e memória, integrando pesquisas e veiculando conteúdos que auxiliam no ensino-aprendizagem de Biofísica e das ciências, de modo geral.

\begin{abstract}
Alessandra Costa
Graduanda em Psicologia (UFPB), integrante do Programa de Educação Popular em Saúde na Comunidade: cultura, comunicação e arte na promoção da cidadania plena (UFPB) e do Laboratório de Percepção, Neurociência e Comportamento - LPNeC (UFPB). Na infância apreciava o cordel por lê-lo como uma história coantada. Hoje, mais que isso admiro como cada verso se faz enquanto um enlace que transborda nossa cultura. O prazer por fazer parte da construção dessa identidade popular é imensurável.
\end{abstract}

\section{Márcia Adelino da Silva Dias}

Docente efetiva do Programa de Pós-Graduação em Ensino de Ciências e Educação Matemática (PPGECEM). Coordenadora adjunta do Programa de Pós-Graduação em Ensino de Ciências e Educação Matemática. Fundadora e coordenadora do Grupo de Estudos da Complexidade e da Vida (GRECOMVIDA)/Campus I/UEPB. Desenvolve pesquisas nas áreas de formação docente, Didática e Ensino de Ciências/Biologia, Educação Ambiental e Etnobiologia.

\section{Karla Patrícia de Oliveira Luna}

Atualmente é professora efetiva da UEPB (Universidade Estadual da Paraíba Campus I). Ministra aulas da disciplina Biofísica na graduação. Faz parte do Mestrado em Ensino de Ciências e Matemática (PPGECEM) da UEPB. Ministra na referida pós graduação aulas das disciplinas Biotecnologia e Práticas de Laboratório para o Ensino de Ciências/Biologia, realizando orientações em ambas as áreas.
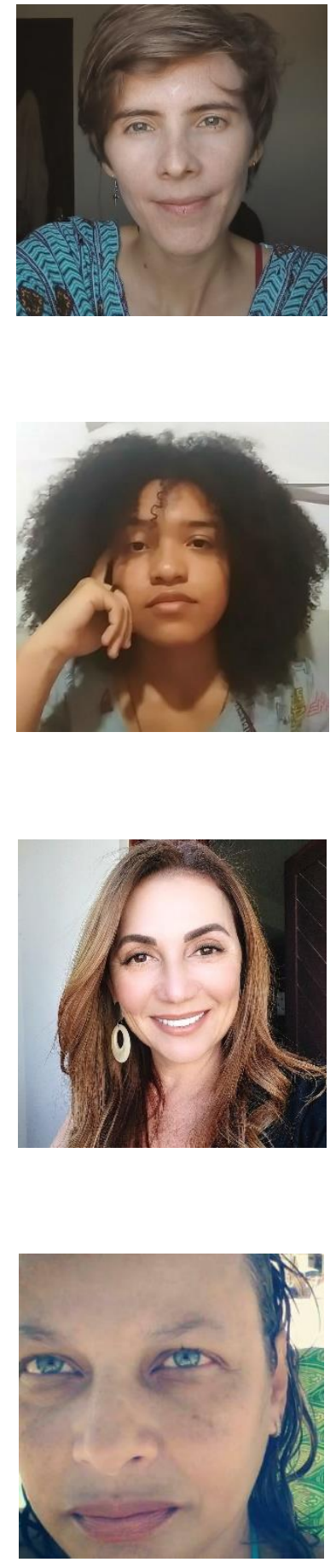

\section{AGRADECIMENTOS}

À Ruthe Gomes pela colaboração na arte da capa deste cordel.

À Capes pelo financiamento parcial para a realização deste projeto. 
MATERIAL DIDÁTICO: A Termodinâmica da Vida

$(\mathrm{cc})$ EY

Este trabalho está licenciado com uma Licença Creative Commons - Atribuição 4.0 Internacional.

Revista SUSTINERE, Rio de Janeiro, v. 9, n.1, p. 405-421, jan-jun, 2021 